\title{
PENDUGAAN BIOMASSA DAN KARBON TERSIMPAN MANGROVE Rhizopora apiculata DAN Sonneratia alba DI DESA SIMAU
}

\section{ESTIMATION OF BIOMASS AND CARBON SAVED ON MANGROVE Rhizopora apiculataANDSonneratia albaIN SIMAU VILLAGE}

\author{
Ronald Kondo Lembang ${ }^{1)}$, Stenly Huliselan ${ }^{2)}$, Fifin Adji ${ }^{3)}$ \\ ${ }^{1}$ Dosen Program Studi Kehutanan, FIATER, Universitas Halmahera \\ ${ }^{2}$ Mahasiswa Program Sarjana Kehutanan,FIATER, Universitas Halmahera \\ Email :klronald4@gmail.com
}

\begin{tabular}{|l|l} 
Diterima: 9 Januari 2019 & Disetujui: 12 Februari 2019
\end{tabular}

\begin{abstract}
Abstrak
Pemanasan global saat ini sudah menjadi persoalan global yang ditandai dengan meningkatnya kandungan karbondioksida pada lapisan atmosfer bumi sehingga membawa dampak terjadinya perubahan iklim yang dapat berpengaruh pada aspek ekologi, sosial, dan ekonomi. Keberadaan hutan sangat penting sebagai pereduksi gas $\mathrm{CO}_{2}$ melalui proses fotosintesis dan dapat menyimpan karbon dalam bentuk biomassa, salah satunya hutan mangrove. Penelitian ini bertujuan untuk menentukan jumlah biomassa total atas permukaan dan karbon tersimpan pada mangrove jenis Rhizoporan apiculata dan Sonneratia alba. Metode yang digunakan adalah metode jalur berpetak dengan membuat jalur sepanjang 100 m kemudian membaginya dalam petak - petak berukuran $10 \times 10 \mathrm{~m}$ yang ditentukan secara acak. Pendugaan biomassa menggunakan persamaan allometrik yang telah dikembangkan sebelumnya pada kedua jenis tersebut. Hasil penelitian menunjukkan besar biomassa atas permukaan yang terkandung pada jenis Rhizopora apiculata sebesar 7,80 ton/ha dan total simpanan karbon sebesar 3,67 ton/ha sedangkan pada jenis Sonneratia alba, jumlah biomassa atas permukaan sebesar 3,33 ton/Ha dan total simpanan karbon sebesar 1,5 ton/ha
\end{abstract}

Kata Kunci: Biomassa Karbon,Rhizopora apiculata, Sonneratia alba

\begin{abstract}
Global warming is now a global issue marked by the increase of carbon dioxide content in the Earth's atmosphere, so that the impact of climate change can affect the ecological, social and economic aspects. The existence of forests is very important as a reducer of $\mathrm{CO}_{2}$ gas through photosynthesis process and can store carbon in the form of biomass, one of mangrove forest. This study aims to determine the total amount of biomass on surface and carbon stored in Rhizoporan apiculata mangrove and Sonneratia alba. The method used is a pathway method by creating a path along 100 meters and then dividing it in $10 \times 10$ meters randomly determined plots. Biomass estimation uses previously developed allometric equations in both types. The results showed that the biomass on surface contained in the Rhizopora apiculata type was 7.80 tons/ha and the total carbon deposit was 3.67 tons/ha, while in the Sonneratia alba type, the amount of surface biomass was 3.33 tons/ha and the total carbon storage of 1.5 tons / ha.
\end{abstract}

Keywords: Biomass, Carbon, Rhizopora apiculata, Sonneratia alba 


\section{PENDAHULUAN}

Hutan di Indonesia memiliki peranan yang cukup penting dalam menjaga ekosistem lingkungan dunia. Hutan bakau atau biasa kita sebut juga hutan mangrove merupakan salah satu tipe hutan dari berbagai jenis hutan di Indonesia. Hutan mangrove merupakan salah satu tumbuhan yang melepaskan emisi ke udara lebih kecil dari pada hutan di daratan, karena pembusukan serasah tanaman aquatictidak melepaskan karbon. Berdasarkan penelitian hutan mangrove atau hutan bakau dapat menyimpan karbon sebanyak 800-1.200 Mg ha-1 (Purnobasuki, 2012).

Mangrove merupakan salah satu potensi yang menjadi parameter untuk dikaji dari ekosistem blue carbon. Peran mangrove dalam kaitannya dengan blue carbonlebih ditekankan sebagai upaya mangrove memanfaatkan $\mathrm{CO}_{2}$ untuk proses fotosintesis dan menyimpannya dalam stok biomassa dan sedimen sebagai upaya mitigasi perubahan iklim. Dalam proses fotosintesis, $\mathrm{CO} 2$ dari atmosfer di ikat oleh vegetasi dan disimpan dalam bentuk biomassa.

Carbon sink berhubungan erat dengan biomassa tegakan. Jumlah biomassa suatu kawasan diperoleh dari produksi dan kerapatan biomassa yang diduga dari pengukuran diameter, tinggi, dan berat jenis pohon. Biomassa dan carbon sink pada hutan tropis merupakan jasa hutan diluar potensi biofisik lainnya,dimana potensi biomassa hutan yang besar adalah menyerap dan menyimpan karbon guna pengurangan CO2 di udara (Darusman, 2006).

Desa Simau merupakan salah satu wilayah di Kecamatan Galela yang terletak pada wilayah pesisir, memiliki hutan mangrove yang cukup luas yang dapat dijadikan sebagai salah satu kawasan dengan fungsi penyangga dalam upaya mengatasi atau memitigasi dampak dari perubahan iklim. Kawasan mangrove yang ada sekarang di Desa Simau telah dimanfaatkan oleh masyarakat untuk kebutuhan hidup masyarakat, mangrove ditebang untuk dijadikan kayu bakar, juga untuk keperluan sebagai tiang penyangga tempat pengelolaan buah kelapa, masyarakat setempat menyebutnya dengan istilah "parapara". Jenis mangrove yang dominan pada kawasan tersebut adalah jenis Rhizopora apiculata dan Sonneratia alba.

Aktifitas masyarakat Desa Simau yang berlebihan terhadap tegakan mangrove, dapat memberikan dampak terhadap fungsi dari hutan mangrove tersebut, baik sebagai tempat berkembangbiaknya beberapa jenis ikan dan kepiting, yang paling utama adalah terganggunya fungsi dari hutan mangrove sebagai penyerap gas karbondioksida $\left(\mathrm{CO}^{2}\right)$ sebagai dampak dari pemanasan global. Penelitian tentang estimasi karbon tersimpan pada tegakan mangrove dirasa penting karena dengan mengetahui jumlah karbon yang mampu diserap oleh mangrove, kita akan lebih memahami manfaat ekologi mangrove sebagai penyerap karbon sehingga usaha konservasi mangrove dalam rangka mengurangi pemanasan global dapat lebih diperhatikan dan ditingkatkan. 


\section{METODE PENELITIAN}

Metode pengambilan data pada ekosistem mangrove berdasarkan Bengen (2003), Kauffman \& Donato (2012). Data struktur komunitas mangrove yaitu menarik garis transek $100 \mathrm{~m}$ kemudian dibuat kuadrat 10x10 m (5 plot) dari tali. Mangrove yang ada di dalam transek diidentifikasi, dihitung jumlah tegakan pohon, besar diameter pohon.

\begin{tabular}{|c|c|c}
\hline $10 \mathrm{~m}$ & & $10 \mathrm{~m}$ \\
& $10 \mathrm{~m}$ & \\
\hline
\end{tabular}

$100 \mathrm{~m}$

Gambar 1. Model Transek Penelitian

Analisis Data

1. Perhitungan Biomassa Atas Permukaan

Untuk menghitung simpanan karbon pohon

Rhizopora apiculata dan Sonneratia alba dilakukan dengan menggunakan persamaan allometrik pendugaan biomassa karbon.

Tabel 1. Persamaan Allometrik Untuk Perhitungan Biomassa Mangrove

\begin{tabular}{|l|l|l|}
\hline \multicolumn{1}{|c|}{$\begin{array}{c}\text { Jenis } \\
\text { Mangrove }\end{array}$} & Persamaan & Sumber \\
\hline $\begin{array}{l}\text { Rhizopora } \\
\text { apiculata }\end{array}$ & $\mathrm{B}=0,043 \mathrm{D}^{2.630}$ & $\begin{array}{l}\text { Amira, } \\
2008\end{array}$ \\
Sonneratia & $\mathrm{B}=$ & \\
alba & $0.3841(\mathrm{D})^{2.101} *^{\circ}$ & \\
& & $\begin{array}{l}\text { Kauffman } \\
\&\end{array}$ \\
& & $\begin{array}{l}\text { Donato, } \\
2012\end{array}$ \\
\hline
\end{tabular}

2. Data hasil pengukuran diameter pohon dimasukkan kedalam persamaan allometrik tersebut sehingga akan diperoleh biomassa dari tiap pohon. Menurut IPCC (2006) konsentrasi karbon yang terkandung dalam bahan organik sebesar $47 \%$, sehingga estimasi jumlah karbon tersimpan yaitu dengan mengalikan 0.47 dengan biomassa

\section{HASIL DAN PEMBAHASAN}

Berdasarkan hasil inventarisasi terhadap jenis Rhizopora apiculata dan Sonneratia alba pada kawasan hutan mangrove di Desa Simau dan dibagi dalam beberapa kelas diameter dapat digambarkan pada Gambar 1 dan Gambar 2 dibawah ini.

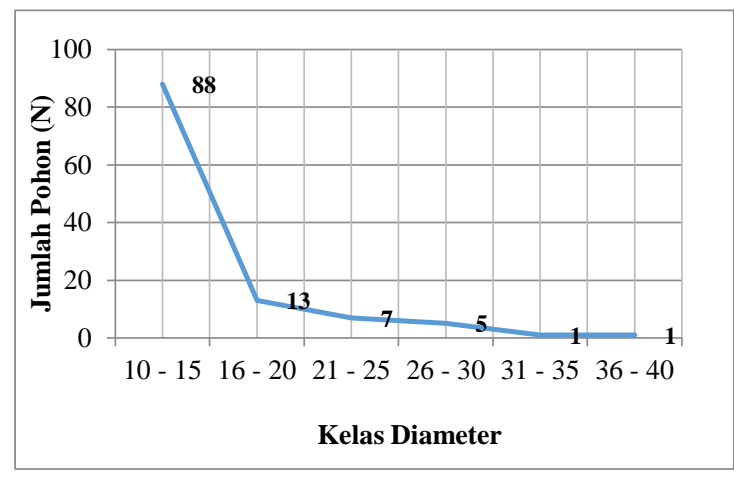

Gambar 2. Sebaran Kelas Diameter Rhizopora A.

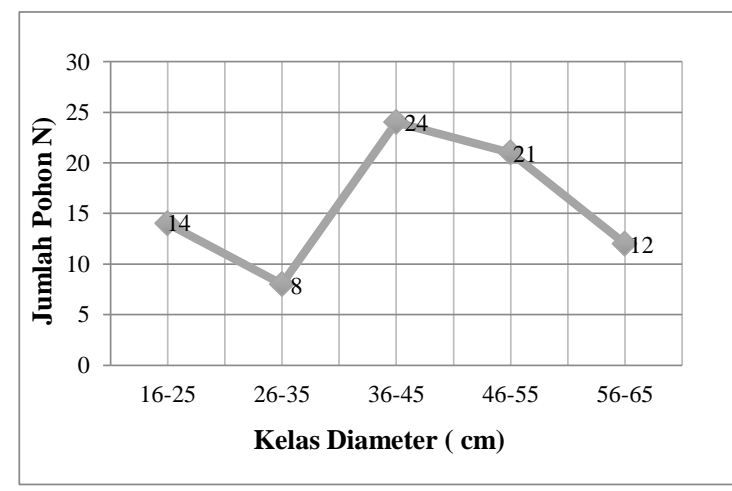

Gambar 3. Sebaran Kelas Diameter Sonneratia Alba

Gambar diatas menunjukkan bahwa seiring bertambahnya diameter pohon, jumlah pohon semakin menurun. Hasil tersebut sesuai 
dengan pernyataan Husch et al. (2002) yang menyatakan distribusi diameter untuk hutan tidak seumur ditandai dengan banyaknya pohon pada kelas diameter kecil yang diikuti denganpenurunan jumlah pohon setiap kenaikan kelas diameter.

Ukuran diameter pohon pada tegakan buatan yang variatif disebabkan pula oleh perbedaan kemampuan adaptasi jenis-jenis pohon yang ditanam sehingga kecepatan pertumbuhan pohon-pohon pada tegakan ini berbeda-beda.

\section{Biomassa Mangrove Jenis Rhizopora apiculata dan Sonneratia alba}

Berdasarkan hasil perhitungan terhadap jumlah biomassa untuk jenis Rhizopora apiculata, jumlah biomassa atas permukaan yang terbesar berada pada kelas diameter 10 $15 \mathrm{~cm}$ dengan total biomassa adalah 2,97 ton/ha dan jumlah biomassa terendah berada pada kelas diameter 31 - 35 cmdengan jumlah biomassa 0,47 ton/ha dan total biomassa atas permukaan pada Rhizopora apiculata berjumlah 7,80 ton/ha. Sedangkan pada jenis Sonneratia alba, jumlah biomassa terbesar berada pada kelas diameter 46 - $55 \mathrm{~cm}$ sebesar 1,2 ton/ha. Jumlah biomassa pada kedua jenis mangrove tersebut dapat dilihat pada Gambar 3 dan 4 dibawah ini.

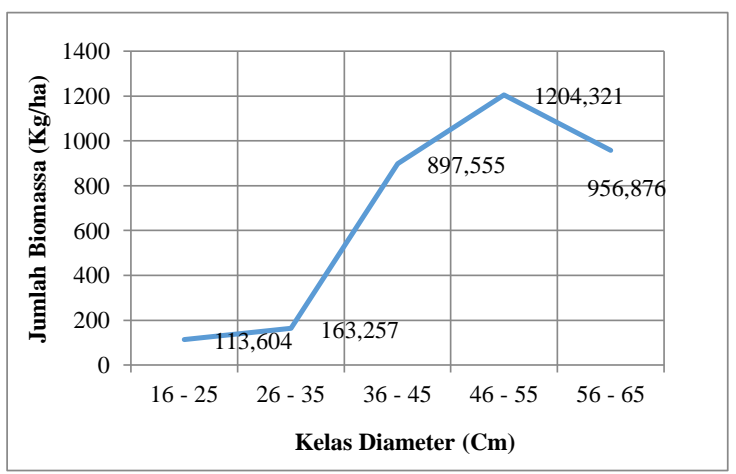

Gambar 4. Jumlah Biomassa Rhizopora apiculata

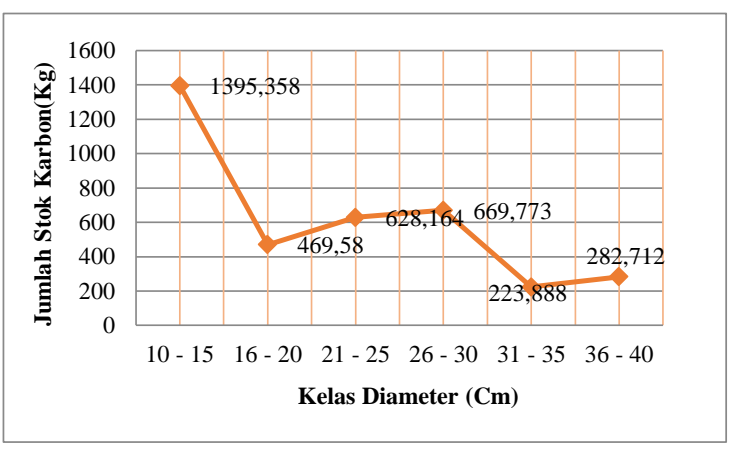

Gambar 5. Jumlah Biomassa Sonneratia alba

Biomassa tegakan pohon sangat mempengaruhi potensi karbon tersimpan. Secara tidak langsung semua parameter yang mempengaruhi biomassa akan berpengaruh juga terhadap simpanan karbon pada suatu tegakan. Parameter yang mempengaruhi biomassa pada suatu ekosistem ialah diameter batang, kerapatan individu, keragaman jenis pohon, dan jenis tanah. Kerapatan pohon yang ada pada suatu wilayah akan mempengaruhi peningkatan cadangan karbon melalui peningkatan biomassa (Rahayu,dkk2007).

Nilai dari biomassa masing-masing kelas diameter berbeda-beda hal tersebut dipengaruhi oleh jumlah pohon pada masingmasing kelas diameter.Semakin tinggi kerapatan pohon semakin besar kandungan biomassa pada suatu areal. Selain jumlah pohon diameter pohon juga mempengaruhi nilai biomassa, semakin besar diameter pohon semakin besar pula biomassa yang disimpan.Secara umum biomassa tiap bagian pohon terbesar diperoleh pada pohon diameter yang palingbesar (Wahyu 2002). Hal tersebut berkaitan dengan prosesfotosintesis dimana tumbuhan menyerap $\mathrm{CO} 2$ dan merubahnya 
menjadi senyawa organik. Hasil fotosintesis disimpan pada bagian-bagian pohon serta digunakan untuk melakukan pertumbuhan diameter dan tinggi. Batang pohon merupakan bagian berkayu tempat penyimpanan cadangan hasil fotosintesis terbesar sehingga hal tersebut menunjukan bahwa pertumbuhan diameter berhubungan dengan pertambahan biomassa.

\section{Jumlah Stock Karbon Mangrove Jenis Rhizopora apiculata dan Sonneratia alba}

Stock karbon merupakan proses penimbunan karbon ( $\mathrm{C}$ ) dalam tubuh tanaman hidup yang dinamakan proses sekuestrasi ( $C$ sequestration) yang disimpan dalam tubuh tanaman pada suatu lahan dapat menggambarkan banyaknya $\mathrm{CO} 2$ di atmosfer yang diserap oleh tanaman ( Hariah K, Dkk. 2011). Berdasarkan hasil pengolahan data, bahwa nilai simpanan karbon untuk mangrove jenis Rhizopora apiculata sebesar 3,67 ton/ha. Sedangkan pada jenis Sonneratia alba memiliki nilai simpanan karbon sebesar 1,57 ton/ha. Hal ini sesuai dengan pernyataan Hairah dan Rahayu (2007) yang menyatakan stock karbon akan mengalami peningkatan karena tergantung dari besarnya biomassa. Semakin besar kandungan biomassa maka stok karbon akan semakin besar.

\section{KESIMPULAN DAN SARAN}

\section{Kesimpulan}

Jumlah biomassa atas permukaan pada mangrove jenis Rhizopora apiculata di Desa Simau sebesar 7,80 ton/ha, sedangkan untuk mangrove jenis Sonneratia alba sebesar 3,33 ton/ha. Nilai simpanan karbon pada mangrove jenis Rhizopora apiculata berjumlah 3,67ton/ha dan untuk nilai simpanan karbon pada mangrove jenis Sonneratia alba adalah 1,5 ton/ha.

\section{Saran}

Perlu dilakukan upaya-upaya konservasi mangrove di Desa Simau

\section{DAFTAR PUSTAKA}

Amira S. 2008. Pendugaan Biomassa Jenis Rhizophora apiculata Bl. di Hutan Mangrove Batu Ampar Kabupaten Kubu Raya, Kalimantan Barat. Skripsi, Fakultas Kehutanan Institut Pertanian Bogor, Bogor.

Bengen DG. 2000. Pedoman Teknis Pengenalan dan Pengolahan Ekosistem Mangrove.Pusat Kajian Sumberdaya Pesisir dan Lautan, Institut Pertanian Bogor. Bogor: IPB.

IPCC (Intergovernmental Panel on Climate Change). 2006. Good Practice Guidance for Land Use, Land Use Change and Forestry. Institute for Global Environmental Strategy, Hayama (Japan).

Kauffman JB \& Donato DC. 2012. Protocols For The Measurement, Monitoring And Reporting Of Structure, Biomass And Carbon Stocks In Mangrove Forests. Working Paper 86.CIFOR. Bogor.

Purnobasuki, H..2012. Pemanfaatan Hutan Mangrove Sebagai Penyimpan Karbon. Buletin PSLUniversitas Surabaya 28 : 3-5.

Rahayu, S. B, Lusiana, B., Noordwijk, M. V. (2007). Pendugaan Cadangan Karbon di Atas Permukaan Tanah pada Berbagai Sistem Penggunaan Lahan di Kabupaten Nunukan, Kalimantan Timur.ICRAF. Bogor.

Wahyu CA. 2002. Model Penaksiran Biomassa Pohon Mahoni (Swietenia Macrophyla) [Skripsi]. Bogor (ID): Institut Pertanian Bogor. Bogor. 